\title{
Role of CT Angiography in the Evaluation of Tumour Vascular Relationship in Patients with Pancreatic Tumours
}

\author{
MONA ZAKY, M.D.*; AHMED ABDALLAH, M.D.**; DINA ABDALLAH IBRAHIM, M.D.*** and \\ DALIA BAYOUMI, M.D.*
}

The Departments of Radio-diagnosis*, Surgical Oncology** and Pathology***, Faculty of Medicine, Mansoura University

\begin{abstract}
Background: Pancreatic cancer is the fourth leading cause of cancer related deaths worldwide. It has poor prognosis especially in locally advanced tumours. Treatment of pancreatic tumours remains a challenge regarding their growth into the adjacent anatomical and vascular structures. Multidetector computed tomography (MDCT) plays an important role in diagnosing of patients with resectable and borderline resectable tumours. Evaluation of borderline resectable tumours should involve the accurate identification of the relationship between the tumour and the surrounding vessels and other vital structures.
\end{abstract}

Aim of Study: Evaluation of the role of CT angiography in the assessment of tumor vascular relationship in patients with pancreatic tumors in order to choose the proper treatment decision.

Material and Methods: This study is a prospective study which was conducted in the Radiology Department of Mansoura University Hospital over the period from August 2016 to September 2019. This study included 79 patients, their ages ranged from 45 to 74 years old with mean age 58.3 years old. All patients were referred from oncology Center of Mansoura University and outpatient surgery clinics. The study was approved by our institution's ethics committee, and all patients gave their informed consent before inclusion in the study. CT scans were obtained with a MDCT scanner (Aquilion 64, Toshiba Medical Systems). CT protocols for pancreatic imaging vary at different institutions but typically include a multiphasic technique with a very thin section imaging and multiplanar reconstruction. Contrast enhanced images include: A late arterial or pancreatic phase and a portal or venous phase after injection of 100-120mL of intravenous non-ionic water soluble contrast material usually at rate of $4-5 \mathrm{~mL} / \mathrm{sec}$.

Results: This study included 79 patients, their ages ranged from 45 to 74 years old with mean age was 58.3 years. The most common affected site in the pancreas was the pancreatic head (47 lesions). All the lesions in our study were histopathological proven malignant. The most common histopathological type in our study was pancreatic adenocarcinoma representing 61 lesions $(77.21 \%)$. As regards the CT appearance of the pancreatic masses, most of the lesions were hypodense (71

Correspondence to: Dr. Mona Zaky, The Department of Radio-diagnosis, Faculty of Medicine, Mansoura University lesions). Detailed evaluation by CT angiography showed that the hepatic artery was involved in 35 cases, the SMA in 49 cases, the celiac trunk in 29 cases and the gartroduodenal artery in 47 cases. There was no arterial vascular involvement in 25 cases. Finally as regards the anatomical variations; accessory right hepatic artery was detected in 11 cases, Accessory left hepatic artery in 12 cases, replaced left hepatic artery in 14 cases, replaced right hepatic artery in 10 cases, replaced common hepatic artery in 9 cases and 23 cases showed no anatomical variants.

Conclusion: Multidetector CT with CT angiography plays a major role in the diagnosis and staging of pancreatic carcinoma. The use of standardized technique and radiologic reporting method can improve the evaluation of the tumorvessel relationship and precisely evaluate the arterial anatomical variants

Key Words: MDCT - CT angiography - Pancreatic carcinoma - Celiac trunk - Superior mesenteric artery.

\section{Introduction}

PANCREATIC cancer (PC) is considered as one of the leading causes of cancer-related deaths among the world according to a 2012 review [1] The best outcome of this tumour is offered by Surgical resection with chemotherapy [2].

Pancreatic cancer diagnosis remains difficult with non-invasive imaging modalities $[3,4]$. At the time of diagnosis, less than $20 \%$ of pancreatic tumours are surgically resectable, and the remaining tumours present with involvement of major vessels and/or distant metastasis [5]. Tumour invasion of the superior mesenteric artery (SMA) and celiac artery is common from pancreatic head tumours because of their proximity, which makes negative resection margin challenging [6]. Vascular involvement was considered as a sign of unresectability for pancreatic tumours historically. However, since the early 1990s, researchers showed that the survival of patients undergoing negative margin venous resection is equivocal to that of patients undergoing 
pancreaticoduodenectomy and is superior to locally advanced tumours treated without surgical resection [7]. Some studies showed that endoscopic ultrasound has higher specificity and sensitivity than MRI and CT in the diagnosis of pancreatic tumours, especially for tumours $(<2 \mathrm{~cm})$. However, it is operator dependent and invasive technique $[8,9]$ MDCT affords sub-millimeter scanning and reconstruction and post processing techniques, such as multiplanar reformatting and CT angiography (CTA) which allows accurate assessment of the exact vascular involvement and identification of anatomic variations [10-12]

The importance of common hepatic artery variations, celiac axis and origin of middle hepatic artery has been of great interest since 1756 when Haller described celiac axis variations. Michel described the classification of anatomic variation of hepatic artery based on the results of 200 cadavers in 1955 [13] while in 1969, Vandamme et al., did research on hepatic artery anomalies on 156 cadavers [14]. Suzuki et al., published their results based on angiographic study of 200 patients and investigated the importance of hepatic artery variations in 1971 [15] Song et al., published their work on celiac axis and hepatic artery variations in 5002 patients and this was in 2010 [16]. Sureka et al., evaluated the anatomic variations of celiac axis, gartroduodenal artery, common hepatic artery, right, middle and left hepatic artery and by using spiral computed tomography [17]

With improvements in neoadjuvant therapies together with development of new vascular reconstruction techniques have made disease with border line respectability potentially respectable $[18]$.

Multidisciplinary team including surgeons, oncologists, radiologists, radiation oncologists, and pathologists, is required to improve survival in patients with resectable and borderline resectable diseases. Standardized radiology report is recommended to create uniformity in the evaluation of the tumour among physicians and across institutions [6].

We aimed in this study: Evaluation of the role of CT angiography in the assessment of tumor vascular relationship in patients with pancreatic tumors in order to choose the proper treatment decision.

\section{Patients and Methods}

This study is a prospective study which was conducted in the Radiology Department of Mansoura University Hospital over the period from
August 2016 to September 2019. This study included 79 patients, their ages ranged from 45 to 74 years old with mean age 58.3 years old.

All patients were referred from oncology Center of Mansoura University and outpatient surgery clinics.The study was approved by our institution's ethics committee, and all patients gave their informed consent before inclusion in the study.

\section{Inclusion criteria:}

Patients with suspicious pancreatic lesion, either clinically or by ultrasound examination.

\section{Exclusion criteria:}

- Un-cooperative patients.

- Patients with hypersensitivity to the contrast agents.

- Patients with renal impairment.

All the patients underwent the following:

I- Full history (at both Oncology Center and radiology departments) including:

- Onset, course and duration of the present complaint.

- History of previous radiological examination

- Local and general examination.

The patients in our study had variable clinical presentations as shown in Table (1); 37 patients presented with jaundice, 12 patients presented by, 10 patients presented with cachexia, 8 patients presented with gastric outlet obstruction.

Table (1): Showing the clinical presentations of the patients.

\begin{tabular}{lc}
\hline Clinical presentation & Number \\
\hline Jaundice & 37 \\
Abdominal pain & 24 \\
Cachexia & 10 \\
Gastric outlet obstruction & 8 \\
\hline
\end{tabular}

\section{CT imaging technique:}

CT scans were obtained with a MDCT scanner (Aquilion 64, Toshiba Medical Systems). CT protocols for pancreatic imaging vary at different institutions but typically include a multiphasic technique with a very thin section imaging and multiplanar reconstruction. Contrast enhanced images include: A late arterial or pancreatic phase and a portal or venous phase after injection of 100$120 \mathrm{~mL}$ of intravenous non-ionic water soluble contrast material usually at rate of $4-5 \mathrm{~mL} / \mathrm{sec}$. The late arterial or pancreatic phase is achieved at 3350 seconds for the assessment of peri pancreatic arterial anatomic structures \& optimal evaluation 
of the pancreatic parenchyma, while the portal venous phase, achieved at 60-90 seconds, allows detection of hepatic and distant metastasis \& allows assessment of the venous anatomic structures and their involvement by the tumour [ 9-12]. MDCT may include thick (3-5- $\mathrm{mm}$ ) sections for primary review \& thin $(0.75-1.50-\mathrm{mm})$ sections for image post processing. Post processed images include multiplanar reformatted images (MPR) (coronal and sagittal), maximum intensity projection images (MIP), and volume-rendered (VR) images, which are important in the identification of subtle changes in vascular calibres, together with accurate identification of any anatomic variation. Volume-rendered images assess vessels in the optimal plane for exact tumoral involvement \& variant anatomic structures [9-12]. Knowing normal and variant anatomic structures is crucial to assess exact extent of the disease and to guide surgery for possible vascular reconstruction.

\section{Statistical analysis:}

Descriptive statistical data were calculated for the anthropometric measurements and laboratory data in the form of:

- Mean \pm Standard deviation (SD) for quantitative data.

- Frequency (number and percent) for qualitative data.

\section{Results}

This study included 79 patients, their ages ranged from 45 to 74 years old with mean age 58.3 years old.

According to the site of the lesions, 47 lesions were in the pancreatic head, 15 lesions in the pancreatic body, 9 lesions in the pancreatic tail, 5 lesions in the uncinate process, 3 lesions in the pancreatic neck as shown in Table (2).

Table (2): Showing the distribution of the lesions in the pancreatic parenchyma.

\begin{tabular}{lc}
\hline Site of the lesions & Number of lesions \\
\hline Pancreatic head & 47 \\
Pancreatic body & 15 \\
Pancreatic tail & 9 \\
Uncinate process & 5 \\
Pancreatic neck & 3 \\
\hline
\end{tabular}

All the lesions in our study were biopsied by different methods such as endoscopic ultrasound guided biopsy, upper gastrointestinal tract endoscopic guided biopsy or radiologically guided biopsy. All the lesions were histopathological proven malignant as shown in Table (3).
The most common histopathological type in our study was pancreatic adenocarcinoma representing 61 lesions $(77.21 \%)$, followed by 8 lesions $(10.12 \%)$ mucinous cystadenocarcinoma, then 3 lesions $(3.79 \%)$ serous cystadenocarcinoma, then 5 lesions $(6.32 \%)$ acinar cell carcinoma and finally 2 lesions $(2.53 \%)$ adenosquamous carcinoma.

Table (3): Showing the histopathological types of the lesions.

\begin{tabular}{ll}
\hline Histopathological types & Number of lesions \\
\hline $\begin{array}{l}\text { Pancreatic adenocarcinoma } \\
\text { (undifferentiated type) }\end{array}$ & 26 \\
$\begin{array}{l}\text { Pancreatic adenocarcinoma } \\
\text { (moderately differentiated type) }\end{array}$ & 19 \\
Pancreatic adenocarcinoma & 16 \\
$\quad$ (well differentiated type) & \\
Pancreatic mucinous cystadenocarcinoma & 8 \\
Pancreatic serous cystadenocarcinoma & 3 \\
Acinar cell carcinoma of pancreas & 5 \\
Adenosquamous carcinoma of pancreas & 2 \\
\hline
\end{tabular}

As regards the CT appearance of the pancreatic masses, most of the lesions were 71 hypodense lesions, then 5 isodense lesions, then 3 hyperdense lesions.

While as regards the relation between peripancreatic vascular arterial structures and pancreatic tumours there where specific items which we were concerned about in the current study and these items were:

1- The vessels involved (celiac trunk, SMA, hepatic artery and gastro-duodenal artery).

2- The type of involvement (tumor-vessel interface) whether fat haziness, abutment or encasement.

3- The degree of involvement (to assess the presence or absence of vascular narrowing and whether it is unilateral or bilateral narrowing).

4- The presence of arterial variant, and its type.

Detailed evaluation by CT angiography is mandatory to cover all of the previously mentioned points to allow accurate assessment of the respectability of the pancreatic tumours and to decide the proper treatment plane for each patient.

In our study the individual vessels involved by pancreatic tumours were: The hepatic artery in 35 cases, the SMA in 49 cases, the celiac trunk in 29 cases and the gartroduodenal artery in 47 cases. There was no arterial vascular involvement in 25 cases. 
Table (4): Showing individual vessel involvemed by malignant pancreatic tumours.

\begin{tabular}{lc}
\hline The vessel involved & Number \\
\hline Hepatic artery & 35 \\
SMA & 49 \\
Celiac trunk & 29 \\
Gastroduodenal artery & 47 \\
\hline
\end{tabular}

\section{1- Celiac trunk:}

The celiac trunk was involved in 29 cases, in 20 cases there was contact between the artery and the tumour tissue either by fat haziness or by direct soft tissue contact but there was no change in the diameter of the celiac trunk as shown in Table (5). While in 9 cases there was narrowing of the arterial lumen, 6 cases showed unilateral luminal narrowing and 3 cases showed bilateral luminal narrowing. The distance of narrowing from the aorta and the ratio of luminal stenosis was also carefully assessed.

Table (5): Showing different types of the tumour interface with the celiac trunk.

\begin{tabular}{lc}
\hline The degree of involvement & Number \\
\hline Fat haziness less than 180 degree & 5 \\
Fat haziness more than 180 degree & 4 \\
Soft tissue contact less than 180 degree & 11 \\
Soft tissue contact more than 180 degree & 9 \\
\hline
\end{tabular}

\section{2- SMA:}

The SMA was involved in 49 cases, in 37 cases there was contact between the artery and the tumour tissue either by fat haziness or by direct soft tissue contact but there was no change in the diameter of the celiac trunk as shown in Table (6). While in 12 cases there was narrowing of the arterial lumen, 7 cases showed unilateral luminal narrowing and 5 cases showed bilateral luminal narrowing. Also involvement of the first order branch of the SMA was accurately assessed, and it was involved in 25 cases and not involved in 24 cases.

Table (6): Showing different types of the tumour interface with the SMA.

\begin{tabular}{lc}
\hline The degree of involvement & Number \\
\hline Fat haziness less than 180 degree & 6 \\
Fat haziness more than 180 degree & 11 \\
Soft tissue contact less than 180 degree & 20 \\
Soft tissue contact more than 180 degree & 12 \\
\hline
\end{tabular}

\section{3- Hepatic artery:}

The hepatic artery was involved in 35 cases, in 29 cases there was contact between the artery and the tumour tissue either by fat haziness or by direct soft tissue contact but there was no change in the diameter of the celiac trunk as shown in Table (7). While in 6 cases of them there was narrowing of the arterial lumen, 4 cases showed unilateral luminal narrowing and 2 cases bilateral luminal narrowing. The extent of the involved segment of the artery was also assessed to define which segment of the artery is involved whether the common hepatic artery (it was involved 25 cases), hepatic artery proper (it was involved in 19 cases) or the hepatic artery bifurcation (it was involved in 17 cases).

Table (7): Showing different types of the tumour interface with the hepatic artery.

\begin{tabular}{ll}
\hline The degree of involvement & Number \\
\hline Fat haziness less than 180 degree & 5 \\
Fat haziness more than 180 degree & 6 \\
Soft tissue contact less than 180 degree & 18 \\
Soft tissue contact more than 180 degree & 6 \\
\hline
\end{tabular}

\section{4- The gartroduodenal artery:}

The gartroduodenal artery was assessed for its involvement and whether its lumen is patent or occluded. This artery was almost involved in most of the cases of pancreatic head tumours (49 cases). Its lumen was still patent in 12 cases and narrowed in 30 cases and near totally occluded in 7 cases.

\section{5- Types of arterial variants:}

In the current study we had different types of anatomical variants as shown in Table (8).

Table (8): Showing different types different types of anatomical variants in our study.

\begin{tabular}{lc}
\hline Type of the anatomical variant & Number \\
\hline Normal & 23 \\
Accessory right hepatic artery & 11 \\
Accessory left hepatic artery & 12 \\
Replaced left hepatic artery & 14 \\
Replaced right hepatic artery & 10 \\
Replaced common hepatic artery & 9 \\
\hline
\end{tabular}



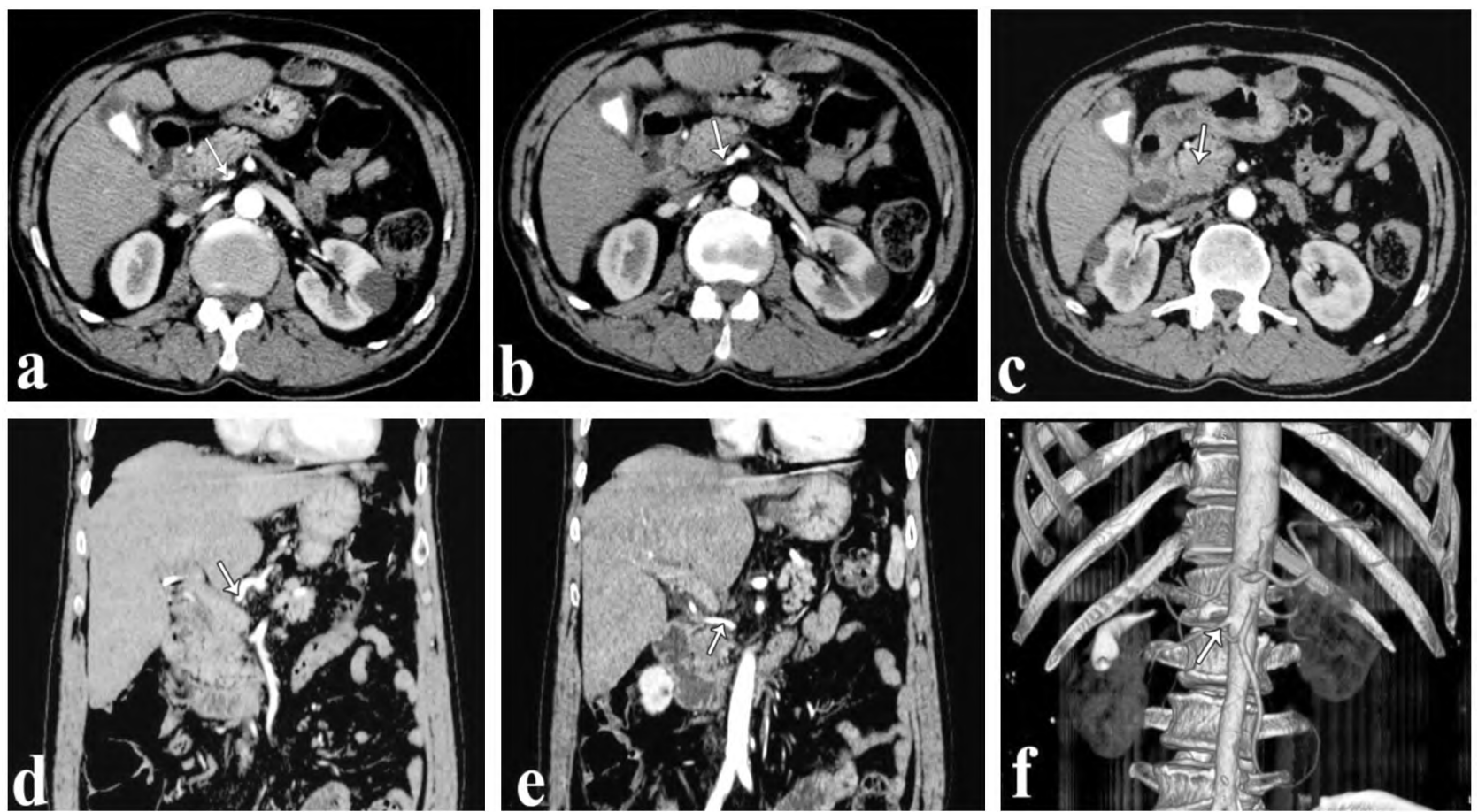

Fig. (1): (A,B,C) Axial CT images showing malignant pancreatic head mass, with replaced right hepatic artery arising from the right side of the SMA. (D,E) Coronal CT images showing the replaced right hepatic artery totally separable from the PHM (F) Volume-rendered CT image showing the replaced right hepatic artery arising from the right side of the SMA.
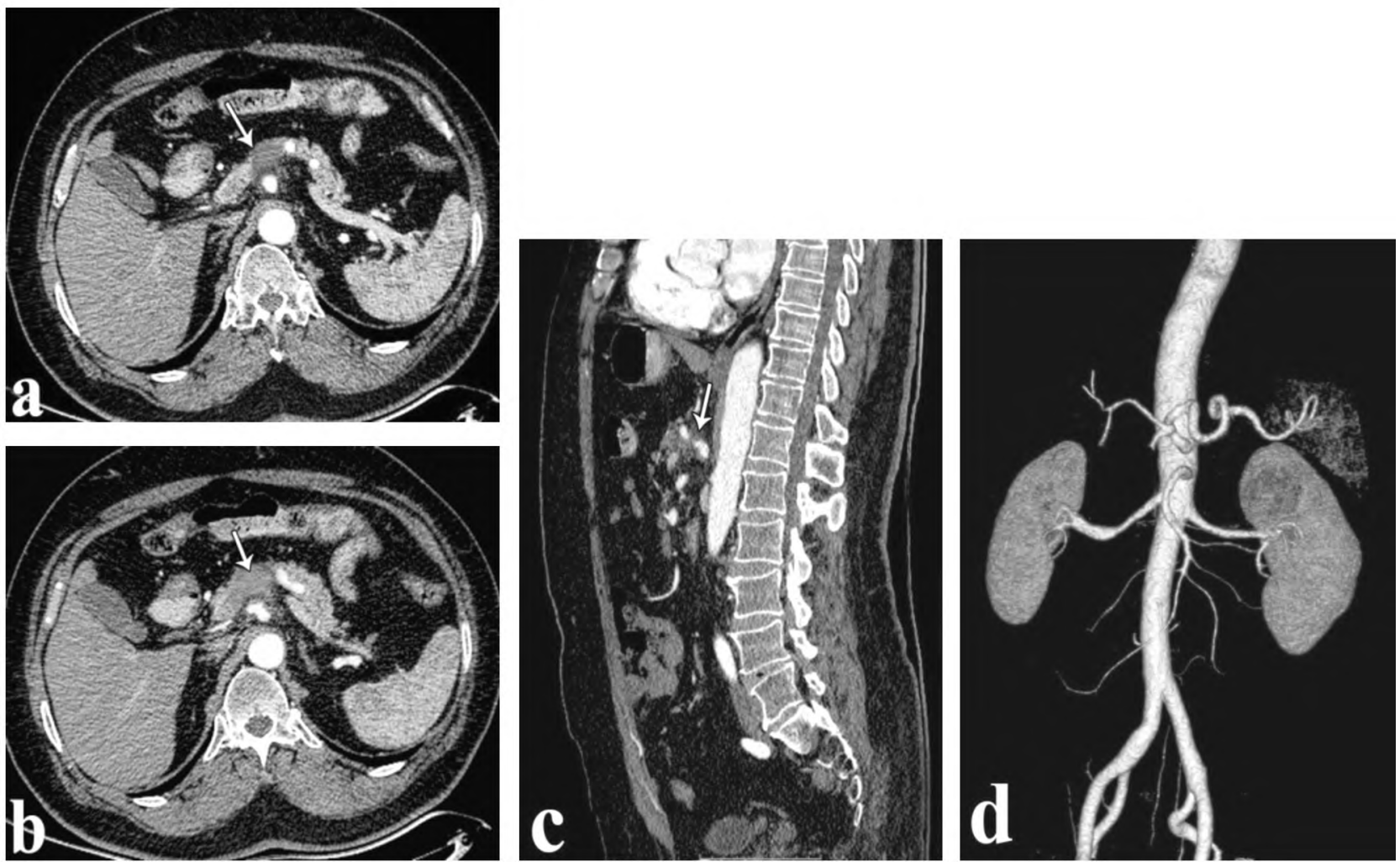

Fig. (2): (A,B) Axial CT images showing malignant pancreatic body mass, contacting the anterior aspect of the celiac trunk (soft tissue contact less than 180 degree) with surrounding fat stranding. (C) Sagittal CT image showing significant narrowing of the celiac trunk. (F) Volume-rendered CT image showing the normal anatomy of the celiac trunk and SMA (no detected anatomical variant). 

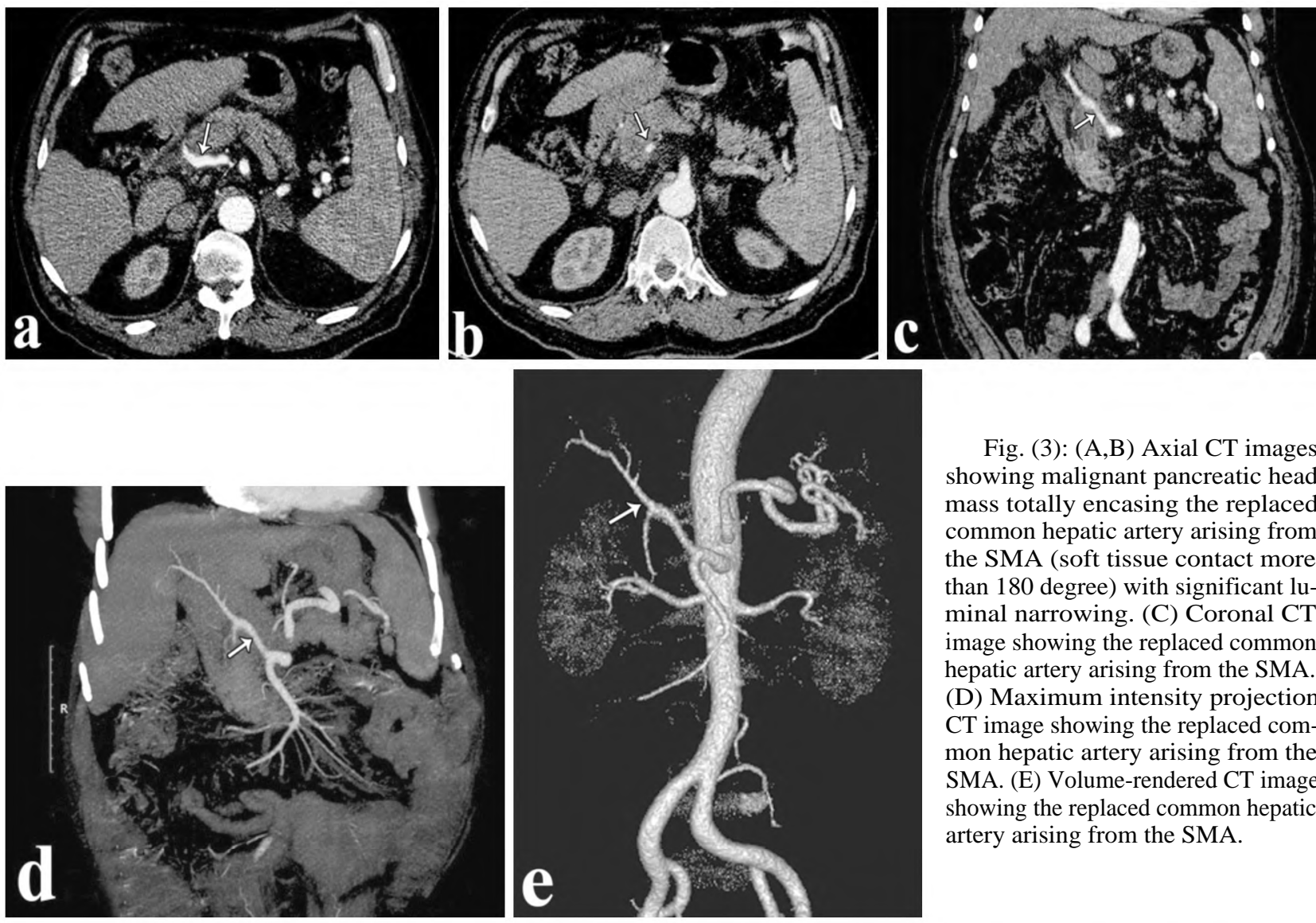

Fig. (3): (A,B) Axial CT images
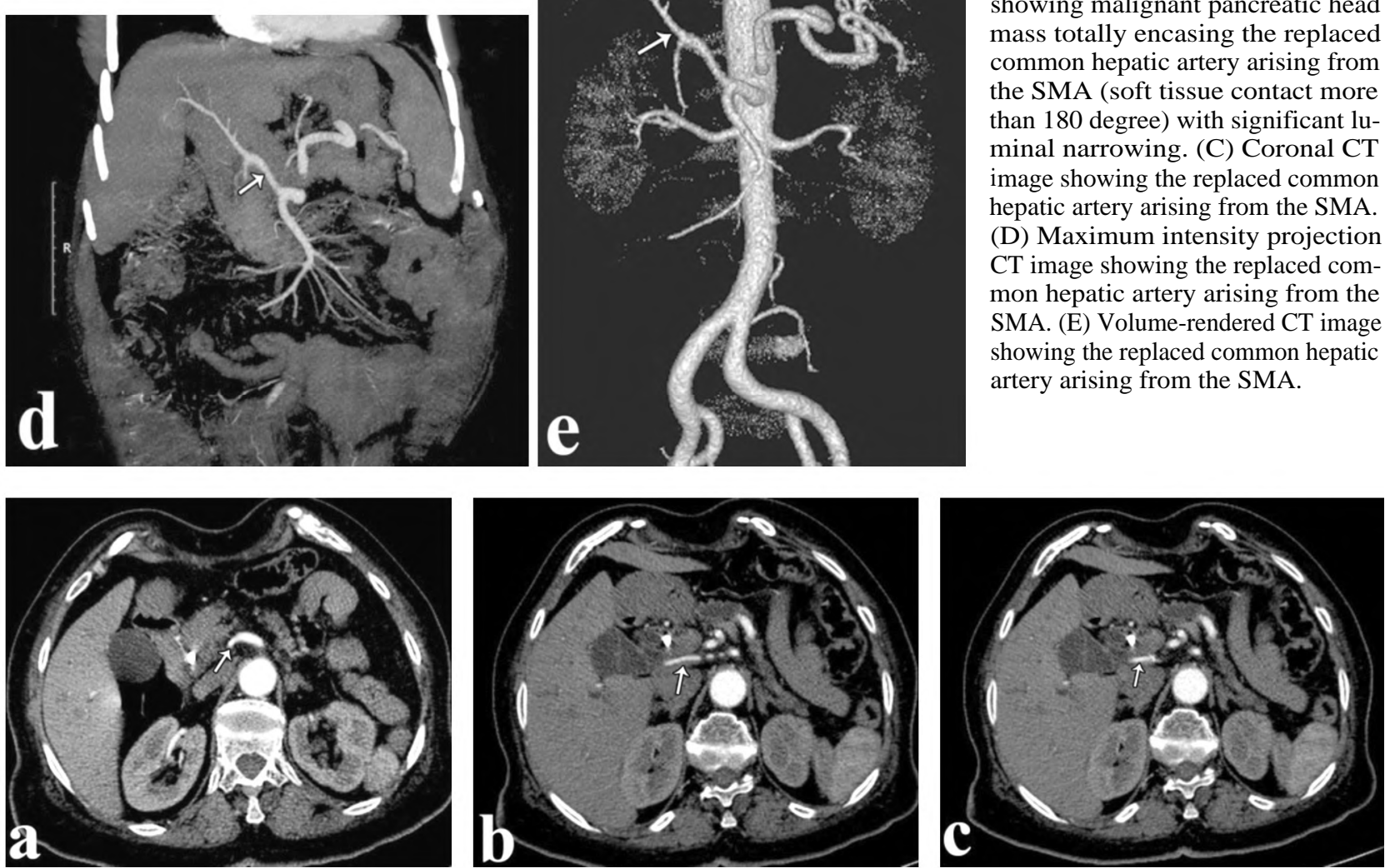

Q
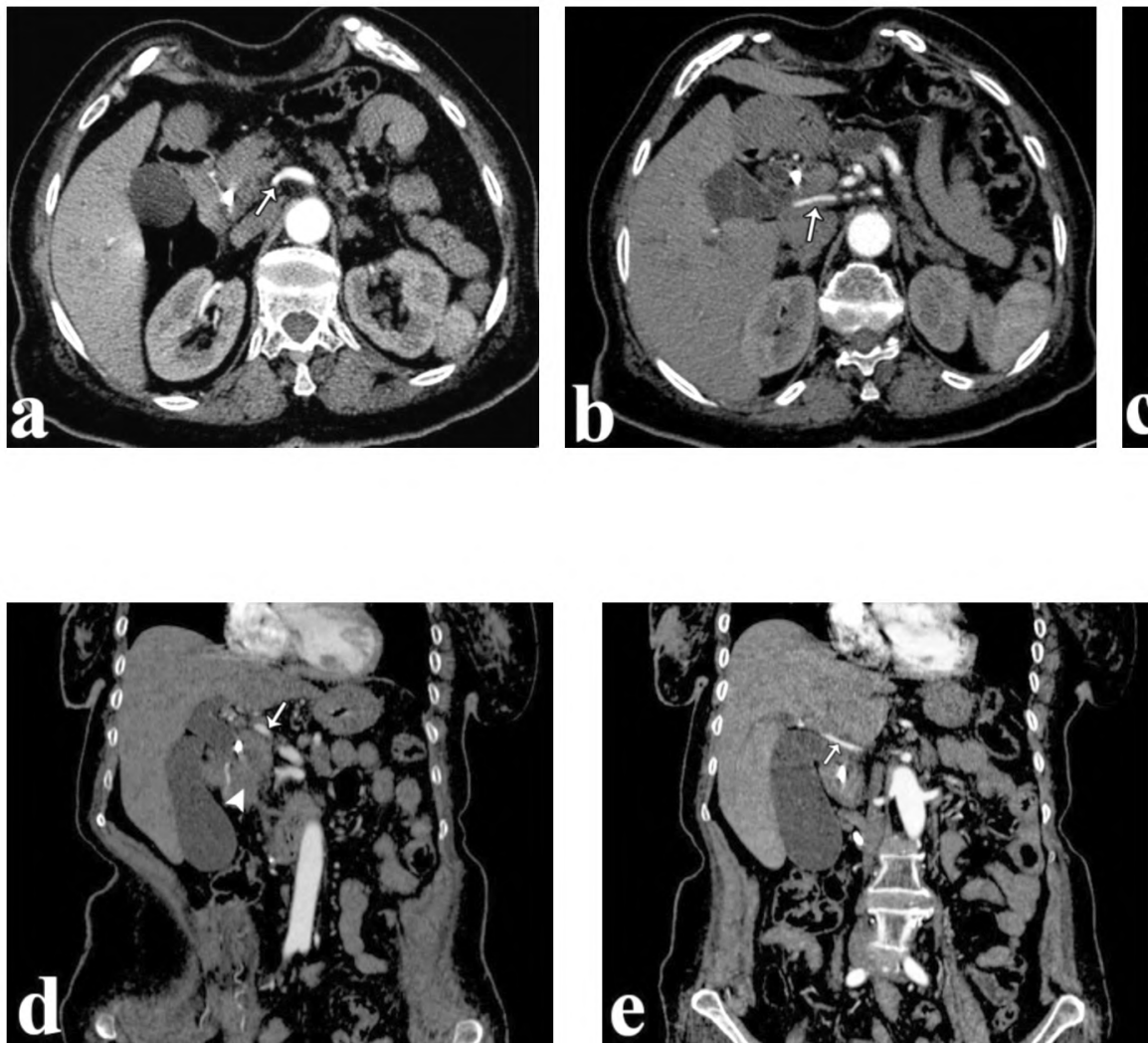
showing malignant pancreatic head mass totally encasing the replaced common hepatic artery arising from the SMA (soft tissue contact more than 180 degree) with significant luminal narrowing. (C) Coronal CT image showing the replaced common hepatic artery arising from the SMA. (D) Maximum intensity projection CT image showing the replaced common hepatic artery arising from the SMA. (E) Volume-rendered CT image showing the replaced common hepatic artery arising from the SMA.
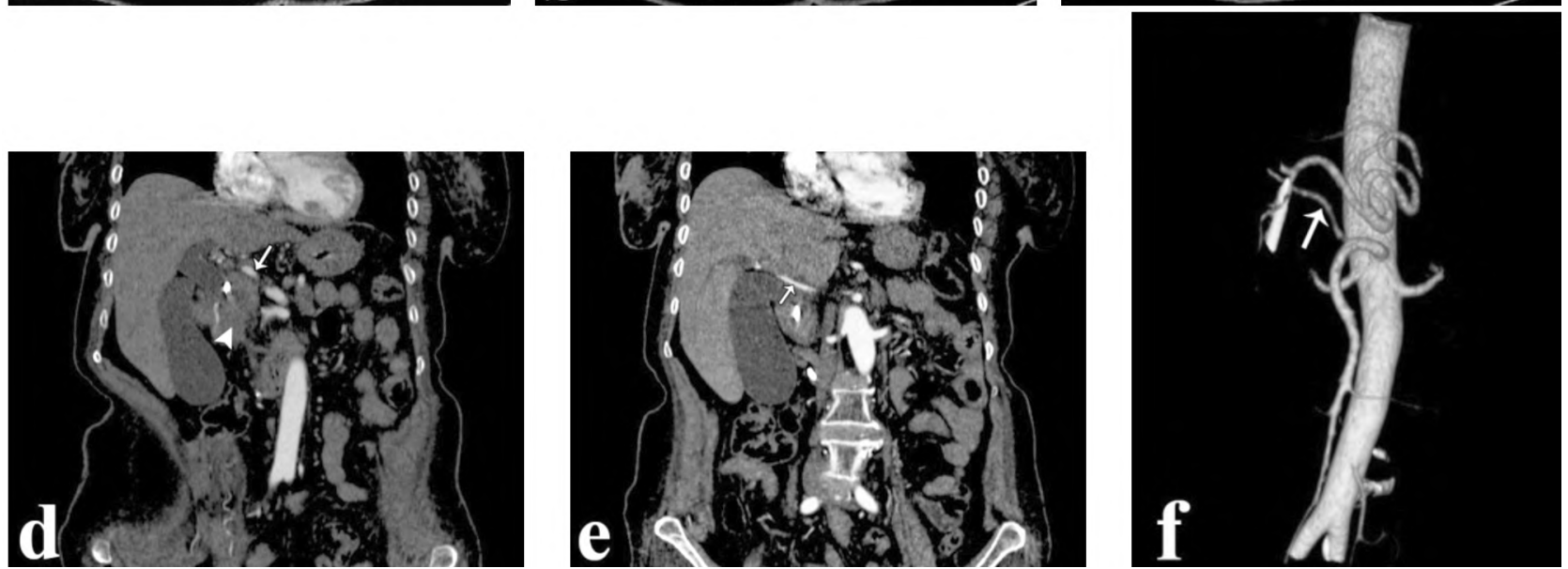

Fig. (4): (A,B,C) Axial CT images showing accessory right hepatic artery arising from the SMA. (D,E) Coronal CT images showing malignant pancreatic head mass (arrow head) totally separable from the accessory right hepatic artery arising from the SMA (arrow). (F) Volume-rendered CT image showing the accessory right hepatic artery arising from the SMA. 

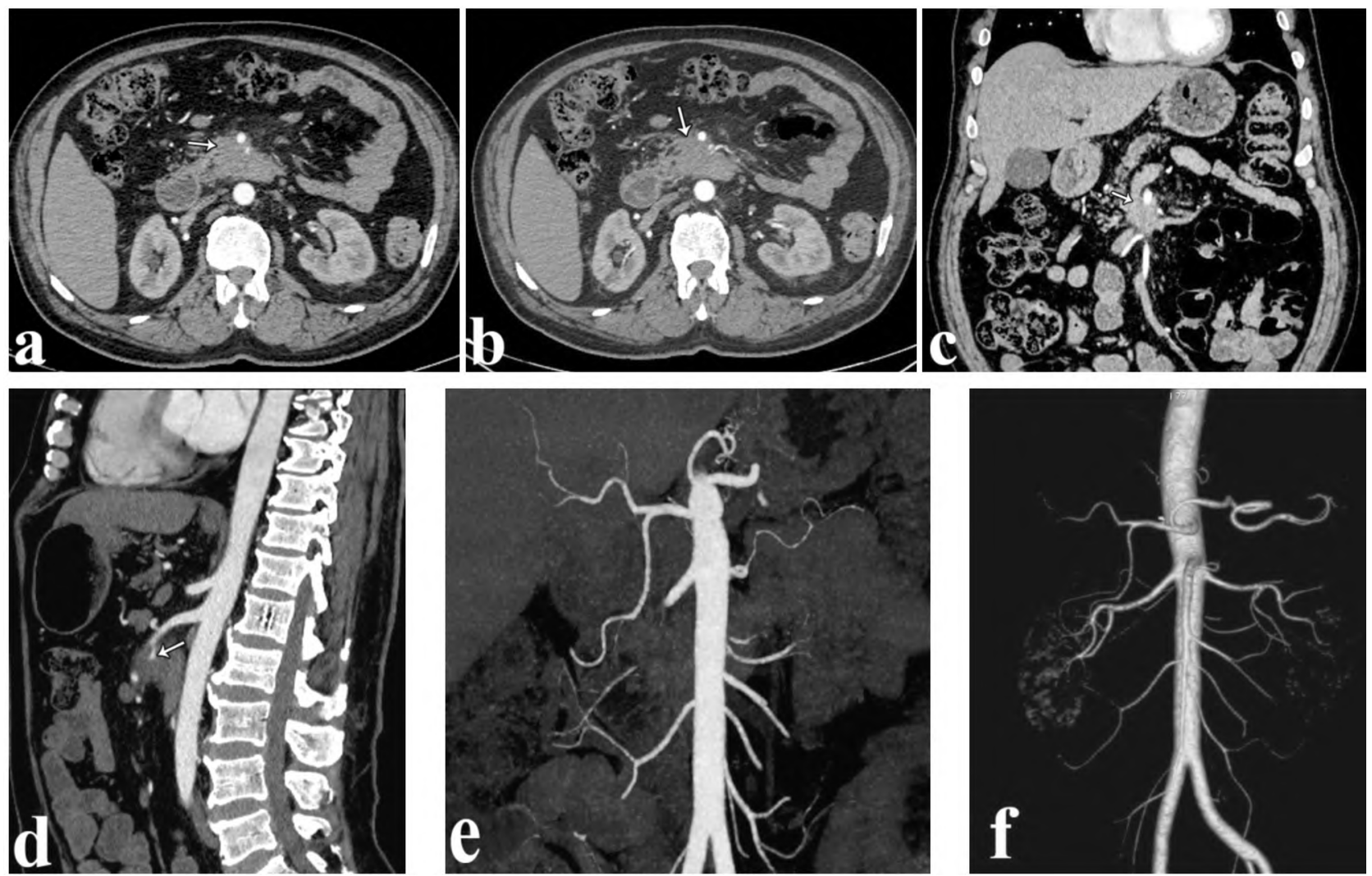

Fig. (5): (A,B) Axial CT images showing malignant pancreatic body mass totally encasing the SMA (soft tissue contact more than 180 degree) and its first order branch (the superior pancreatico-duodenal artery that showed significant luminal narrowing). (C,D) Coronal and sagittal CT images showing malignant pancreatic body mass totally encasing the SMA. (E) Maximum intensity projection CT image normal vascular anatomy. (F) Volume-rendered CT image showing the normal vascular anatomy.
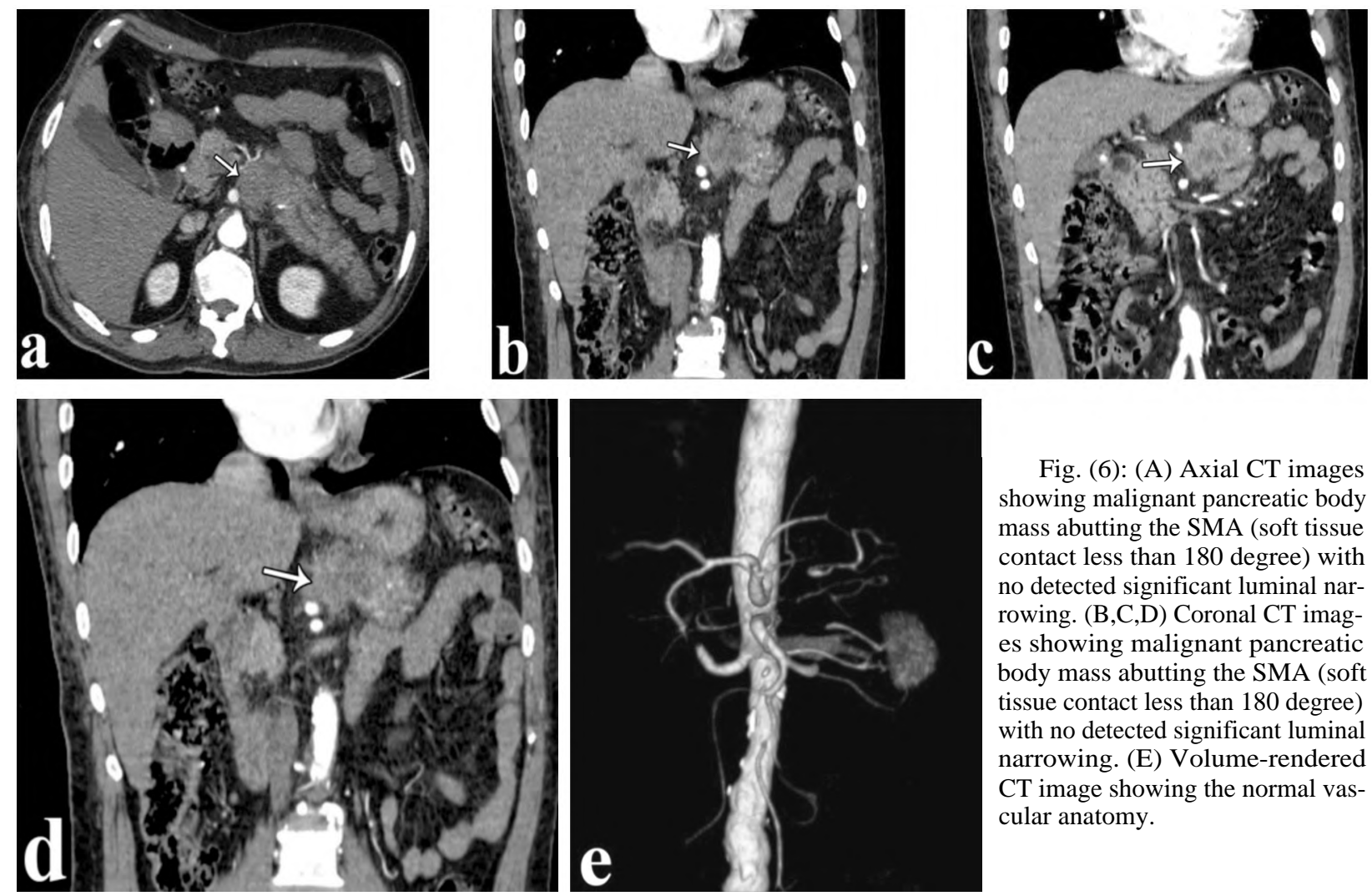

Fig. (6): (A) Axial CT images showing malignant pancreatic body mass abutting the SMA (soft tissue contact less than 180 degree) with no detected significant luminal narrowing. (B,C,D) Coronal CT images showing malignant pancreatic body mass abutting the SMA (soft tissue contact less than 180 degree) with no detected significant luminal narrowing. (E) Volume-rendered $\mathrm{CT}$ image showing the normal vascular anatomy. 


\section{Discussion}

This study is a prospective study which was conducted in the Radiology Department of Mansoura University Hospital over the period from August 2016 to September 2019. This study included 79 patients, their ages ranged from 45 to 74 years old with mean age 58.3 years old. All patients were referred from oncology Center of Mansoura University and outpatient surgery clinics. The study was approved by our institution's ethics committee, and all patients gave their informed consent before inclusion in the study.

Pancreatic cancer is one of the leading causes of death worldwide. It is considered the fourth most common cause of cancer-linked mortality in the United States. Pancreatic ductal adenocarcinoma (PDAC) is the most common pathological type and forms more than $90 \%$ of all pancreatic cancers. Multiple genetic and life related risk factors play an important role in the development of PDAC which include smoking, diabetes, obesity, high fat diet, past history of chronic pancreatitis, certain types of infections and abdominal surgeries [19].

Presenting signs or symptoms of PDAC vary according to the location of the pancreatic mass; however, the disease can present in late stages with no prior signs or symptoms. In the current study the most common symptom was obstructive jaundice, followed by typical epigastric abdominal pain, then the malignant cachexia and gastric outlet obstruction. These finding are in agreement with many clinical studies that showed that most of the pancreatic tumors affect the pancreatic head, so they are typically presented with obstructive jaundice as early clinical symptom [20].

The location of the tumor in the pancreatic parenchyma determines its way of spread and the lymph nodes involved in the disease, when the tumor is located in the anterior part of the pancreatic head, it usually extends along the anterior pancreatico-duodenal and the proper hepatic artery. If the tumor is located in the posterior part of the pancreatic head, it extends along the posterior pancreaticoduodenal vein toward the inferior surface of the portal vein. A pancreatic tumor in the uncinate process grows within the inferior pancreaticoduodenal arcade along the posterior aspect of the superior mesenteric artery or extends into the jejunal mesentery. If the tumors in the pancreatic body and tail, it generally infiltrates the celiac trunk, the splenic vessels [21,22]

In our study the most common site affected by the pancreatic tumors was the pancreatic head that was affected in 47 cases and this was in agreement with many studies stating that the pancreatic head is the most affected site and it usually shows early infiltration of the hepatic and gartroduodenal arteries $[\mathbf{2 3 , 2 4 ]}$.

The pathological types of pancreatic carcinoma are classified into epithelial or non-epithelial. Also they are classified according to their biological behaviour into benign, pre-malignant or malignant tumors. Epithelial neoplastic tumor may be either exocrine or endocrine, while the category of exocrine neoplasms is also classified in ductal and acinar neoplasms.

As regards the histopathological types the most common one type in our study was pancreatic adenocarcinoma (PDAC) representing 61 lesions $(77.21 \%)$, as this was in agreement with Schlitter et al., 2017 who stated that Pancreatic ductal adenocarcinoma (PDAC) is actually the most common type of pancreatic malignant neoplastic tumors representing about $90 \%$ of all pancreas neoplasms [6]. Hence, the term of "pancreatic cancer" and "pancreatic ductal adenocarcinoma" are the same and often used synonymously [25]

The PDAC is usually located in the proximal pancreas, while its involvement of the distal parts as the pancreatic body or tail is not common. In PDAC of the pancreatic head, obstruction of the common bile duct can lead to painless jaundice and usually associate with early vascular involvement of the hepatic, SMA and gartroduodenal arteries [26]

The PDAC are further classified into grade 1 (well-differentiated type), grade 2 (moderately differentiated type) and grade 3 (poorly differentiated type) the worst prognosis is usually associated with the poorly differentiated type which is characterized by being very invasive, growing into and extending into the pancreatic ducts. Perineural invasion is also very common finding with these lesions (90\%), as well as the spread into peripancreatic fat planes $[23,24]$. Other types of malignant pancreatic neoplastic masses are relatively uncommon [7] and these was in agreement with our study as the histopathological types other than PDAC represented only $22 \%$ of the pancreatic lesions and they were relatively more common in the pancreatic body and tail.

As regards the CT appearance most of the pancreatic masses are isodense mass with convex infiltrative borders while in CECT in arterial/pancreatic phase: The pancreatic masses are usually poorly enhancing masses with ill-defined 
irregular margins. In portal and delayed phases, most of pancreatic masses show poor enhancement or progressive heterogeneous enhancement. Small pancreatic masses are usually non-deforming and appear isodense with the remaining of the pancreatic parenchyma. Rare CT appearance is complex cystic heterogeneously enhancing masses wit area of haemorrhage and necrosis [22]

The evaluation of arterial vascular involvement in patients with pancreatic carcinoma is one of the key factors that define the possible of respectability of the pancreatic tumors and the multidetector CT angiography is superior to conventional $\mathrm{CT}$ angiography because of the important information which it gives about the course of the vessel within and around the pancreatic parenchyma. Different methods are used for the evaluation of the incomplete or complete neoplastic soft tissue surrounding the peripancreatic vascular structures with assessment of the wall irregularities, and vessel calibre changes [19]. In our study we tried to assess the tumoral encasement of peri-pancreatic arteries using standardized method by the multi-detector CT that showed high sensitivity of up to $80 \%$ and high specificity of $98 \%$ for detection arterial invasion.

The arteries have walls thicker than that of the vein, and the flow rate of blood inside the arteries is higher than its flow inside the vein, so any change in the diameter of the artery or the presence of arterial thrombus carries a higher risk of invasion than those findings in the vein [26]

In our study we evaluated the type of the tumor vascular interface whether it is fat haziness (less than or more than 180 degree) or direct soft tissue contact (less than or more than 180 degree). If there was soft tissue contact more than 180 degre with the arterial lumen, the wall irregularity and the degree of narrowing whether unilateral or bilateral was also assessed.

For detection of the respectability of pancreatic tumors many arteries have to be assessed including celiac trunk, hepatic artery and SMA and gartroduodenal arteries. Our study was in agreement with Shen et al., 2017 and Varadhachary, 2017 as regards the celiac and hepatic artery involvement, they are usually involved as a result of the cephalic growth of PDAC of the pancreatic head and neck. Therefore, sometimes, when a short segment of the hepatic artery is involved close to the origin of the gartroduodenal artery, the lesion can't be resected [27].
Involvement of the celiac trunk is one of the major criteria that affect the locally advanced PDAC either resectable or not. Our study is also in agreement with other studies that showed that the PDAC arising from the neck of the pancreas is more likely to involve the celiac artery and its trifurcation, along with possible involvement of a segment of the hepatic artery. Therefore, it is important to assess the extent of the tumor on the common hepatic artery proximal to the origin of the gartroduodenal artery and to assess also the patency of the gartroduodenal [29-31]

Multidetector CT angiography also provide important information about the course of the vessel within the pancreatic parenchyma and can detect the presence of arterial variants of the celiac and SMA. The replaced right hepatic artery is the most common arterial anatomical variant. Its percent is about $11 \%$ to $21 \%$. In this condition the right hepatic artery originates from the SMA and runs just postero-lateral to the portal vein or passes behind or through the pancreatic head, the accidental injury of the replaced right hepatic artery can cause injury of the bilio-enteric anastomosis during and after surgery [32]

Another common arterial variant is the replaced common hepatic artery which arises from the SMA by a common arterial trunk referred which is called the hepatomesenteric trunk, the incidence of this variant ranges from $0.4 \%$ to $4.5 \%$. The replaced common hepatic artery passes through the pancreatic parenchyma or runs upwards behind the head of the pancreas and to reach the porta hepatis just medial to the CBD in the common site of the gartroduodenal artery [33]. The accidental injury of the common hepatic artery causes biliary leak as well as hepatic ischemia and necrosis [34]

\section{Conclusion:}

Multidetector CT with CT angiography plays a major role in the diagnosis and staging of pancreatic carcinoma. The use of standardized technique and a radiologic reporting method can improve the evaluation of the tumor-vessel relationship and precisely evaluate the arterial anatomical variants.

\section{References}

1- SHRIKHANDE S.V., BARRETO S.G., GOEL M. and ARYA S.: Multimodality imaging of pancreatic ductal adenocarcinoma: A review of the literature. HPB, 14 (10): 658-668, 2012.

2- PÁEZ D., LABONTE M.J. and LENZ H.J.: Pancreatic cancer: Medical management (novel chemotherapeutics). Gastroenterology Clinics, 41 (1): 189-209, 2012. 
3- TAKESHITA K., KUTOMI K., HARUYAMA T., WATANABE A., FURUI S., FUKUSHIMA J. and ASANO T.: Imaging of early pancreatic cancer on multidetector row helical computed tomography. The British Journal of Radiology, 83 (994): 823-830, 2010.

4- YOON S.H., LEE J.M., CHO J.Y., LEE K.B., KIM J.E., MOON S.K. and LEE J. Y.: Small ( 920mm) pancreatic adenocarcinomas: Analysis of enhancement patterns and secondary signs with multiphasic multidetector CT. Radiology, 259 (2): 442-452, 2011.

5- SEUFFERLEIN T., BACHET J.B., VAN CUTSEM E.F.A.U., ROUGIER P. and ESMO Guidelines Working Group: Pancreatic adenocarcinoma: ESMO-ESDO Clinical Practice Guidelines for diagnosis, treatment and followup. Annals of Oncology, 23 (Suppl 7): vii33-vii40, 2012.

6- ZAKY A.M., WOLFGANG C.L., WEISS, M.J., JAVED A. A., FISHMAN, E.K. and ZAHEER A.: Tumor-vessel relationships in pancreatic ductal adenocarcinoma at multidetector CT: different classification systems and their influence on treatment planning. Radiographics, 37 (1): 93-112, 2016.

7- YEKEBAS E.F., BOGOEVSKI D., CATALDEGIRMEN, G., KUNZE C., MARX A., VASHIST Y. K. and SCHNEIDER C.: En bloc vascular resection for locally advanced pancreatic malignancies infiltrating major blood vessels: Perioperative outcome and long-term survival in 136 patients. Annals of Surgery, 247 (2): 300-309, 2008.

8- TAMM E.P., BHOSALE P.R., VIKRAM R., DE ALMEIDA MARCAL L. P. and BALACHANDRAN A.: Imaging of pancreatic ductal adenocarcinoma: State of the art. World Journal of Radiology, 5 (3): 98, 2013.

9- KANEKO O.F., LEE D.M., WONG J., KADELL B.M., REBER H.A., LU D.S. and RAMAN S.S.: Performance of multidetector computed tomographic angiography in determining surgical resectability of pancreatic head adenocarcinoma. Journal of Computer Assisted Tomography, 34 (5): 732-738, 2010.

10- LEE E.S. and LEE J.M.: Imaging diagnosis of pancreatic cancer: A state-of-the-art review. World journal of gastroenterology: WJG, 20 (24): 7864, 2014.

11- WANG F.B., NI J.M., ZHANG Z.Y., ZHANG L., WU W. J., WANG D. and Gong L.: Differential diagnosis of periampullary carcinomas: Comparison of $\mathrm{CT}$ with negative-contrast CT cholangiopancreatography versus MRI with MR cholangiopancreatography. Abdominal Imaging, 39 (3): 506-517, 2014.

12- LI B., ZHANG L., ZHANG Z.Y., NI J.M., LU F.Q., WU W. J. and JIANG C.J.: Differentiation of noncalculous periampullary obstruction: Comparison of CT with negative-contrast CT cholangiopancreatography versus MRI with MR cholangiopancreatography. European Radiology, 25 (2): 391-401, 2015.

13- MICHELS N.A.: Blood supply and anatomy of the upper abdominal organs with a descriptive atlas. Philadelphia (Pa): 7, 1955.

14- VANDAMME J.P.J., BONTE J. and VAN DER SCHUEREN G.: A revaluation of hepatic anil cystic arteries the importance of the aberrant hepatic branches. Cells Tissues Organs, 73 (2): 192-209, 1969.

15- SUZUKI T., NAKAYASU A., KAWABE K., TAKEDA H. and HONJO I.: Surgical significance of anatomic variations of the hepatic artery. The American Journal of Surgery, 122 (4): 505-512, 1971.

16- SONG S.Y., CHUNG J. W., YIN Y. H., JAE H. J., KIM H.C., JEON U.B. and PARK J.H.: Celiac axis and common hepatic artery variations in 5002 patients: Systematic analysis with spiral CT and DSA. Radiology, 255 (1): 278-288, 2010.

17- SUREKA B., MITTAL M.K., MITTAL A., SINHA M., BHAMBRI N.K. and THUKRAL B.B.: Variations of celiac axis, common hepatic artery and its branches in 600 patients. The Indian Journal of Radiology \& Imaging, 23 (3): 223, 2013.

18- GILLEN S., SCHUSTER T., ZUM BÜSCHENFELDE C. M., FRIESS H. and KLEEFF J.: Preoperative/neoadjuvant therapy in pancreatic cancer: A systematic review and meta-analysis of response and resection percentages. PLoS Medicine, 7 (4): e1000267, 2010.

19- FRAMPAS E., DAVID A., REGENET N., TOUCHEFEU Y., MEYER J. and MORLA O.: Pancreatic carcinoma: Key-points from diagnosis to treatment. Diagnostic and Interventional Imaging, 97 (12): 1207-1223, 2016.

20- SABATER L., MUÑOZ E., ROSELLÓ S., DORCARATTO D., GARCÉS-ALBIR M., HUERTA M. and CERVANTES A.: Borderline resectable pancreatic cancer. Challenges and controversies. Cancer Treatment Reviews, 68: 124-135, 2018.

21-FERLAY J., PARKIN D.M. and STELIAROVAFOUCHER E.: Estimates of cancer incidence and mortality in Europe in 2008. European Journal of Cancer, 46 (4): 765-781, 2010.

22-CASSINOTTO C., SA-CUNHA A. and TRILLAUD H. Radiological evaluation of response to neoadjuvant treatment in pancreatic cancer. Diagnostic and Interventional Imaging, 97 (12): 1225-1232, 2016.

23- HRUBAN R.H., TAKAORI K., KLIMSTRA D.S., ADSAY N.V., ALBORES-SAAVEDRA J., BIANKIN A.V. and GOGGINS M.: An illustrated consensus on the classification of pancreatic intraepithelial neoplasia and intraductal papillary mucinous neoplasms. The American Journal of Surgical Pathology, 28 (8): 977-987, 2004.

24-CASCINU S., FALCONI M., VALENTINI V. and JELIC S. GROUP E.G.W.: Pancreatic cancer: ESMO Clinical Practice Guidelines for diagnosis, treatment and followup. Ann. Oncol., 21, 2010.

25- SCHLITTER A.M., SEGLER A., STEIGER K., MICHALSKI C.W., JÄGER C., KONUKIEWITZ B. and REGEL, I.: Molecular, morphological and survival analysis of 177 resected pancreatic ductal adenocarcinomas (PDACs): Identification of prognostic subtypes. Scientific Reports, 7: 41064, 2017.

26- HARTWIG W., HACKERT T., HINZ U., GLUTH A., BERGMANN F., STROBEL O. and WERNER J.: Pancreatic cancer surgery in the new millennium: Better prediction of outcome. Annals of Surgery, 254 (2): 311319, 2011.

27- CHOE K.A. and MCDONALD N.M.: Imaging Evaluation of Borderline Pancreatic Cancer. In Multimodality Management of Borderline Resectable Pancreatic Cancer, (pp. 17-30). Springer, Cham., 2016. 
28- BARNES C.A., CHAVEZ M.I., TSAI S., ALDAKKAK M., GEORGE B., RITCH P.S. and HALL W.A.: Survival of patients with borderline resectable pancreatic cancer who received neoadjuvant therapy and surgery. Surgery, 166 (3): 277-285, 2019.

29- SHEN Y.N., BAI X.L., LI G.G. and LIANG T.B.: Review of radiological classifications of pancreatic cancer with peripancreatic vessel invasion: Are new grading criteria required?. Cancer Imaging, 17 (1): 14, 2017.

30- VARADHACHARY G.R.: Borderline Resectable Pancreatic Cancer. Pancreatic Cancer, 1-21, 2017.

31- EVANS D.B., GEORGE B. and TSAI S.: Non-metastatic pancreatic cancer: Resectable, borderline resectable, and locally advanced-definitions of increasing importance for the optimal delivery of multimodality therapy. Annals of Surgical Oncology, 22 (11): 3409-3413, 2015.
32- NOUSSIOS G., DIMITRIOU I., CHATZIS I. and KATSOURAKIS A.: The main anatomic variations of the hepatic artery and their importance in surgical practice: Review of the literature. Journal of Clinical Medicine Research, 9 (4): 248, 2017.

33- GONG H., MA R., GONG J., CAI C., SONG Z. and XU B.: Distal pancreatectomy with en bloc celiac axis resection for locally advanced pancreatic cancer: A systematic review and meta-analysis. Medicine, 95 (10): 2016.

34- TURRINI O., WIEBKE E.A., DELPERO J.R., VIRET F., LILLEMOE K.D. and SCHMIDT C.M.: Preservation of replaced or accessory right hepatic artery during pancreaticoduodenectomy for adenocarcinoma: Impact on margin status and survival. Journal of Gastrointestinal Surgery, 14 (11): 1813-1819, 2010.

\title{
دور الاشعة الهقطعية بالصبغة فى تقييم

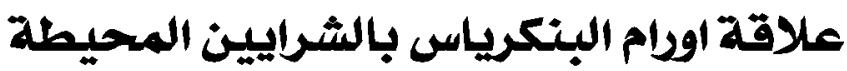

\author{
يعتبر سرطان البنكرياس أحد الأسباب الرئيسية للوفيات المرتبطة بالسرطان فى العالم، حتى الان العلاج الأمثل لهذا الودم الاستئصال

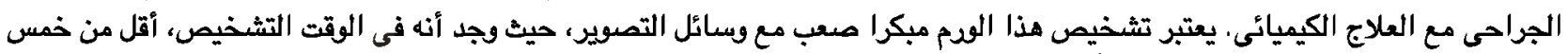

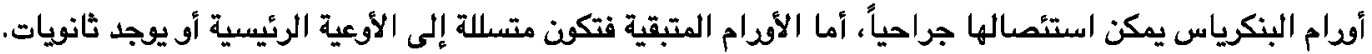

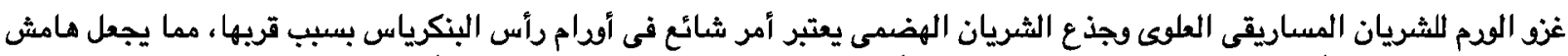

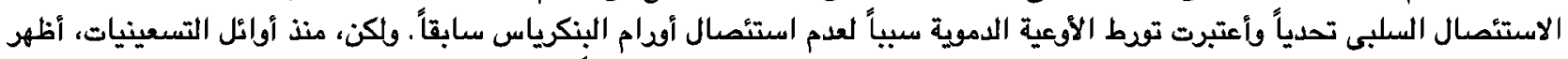

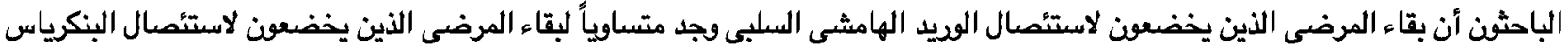

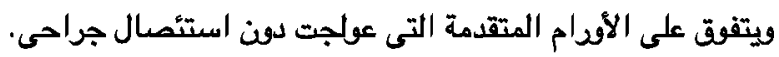 \\ أظهرت بعض الدراسات أن الموجات فوق الصوتية بالمنظار لها خصوصية وحساسية أعلى من التصوير بالرنين المغناطيسي والتصوير

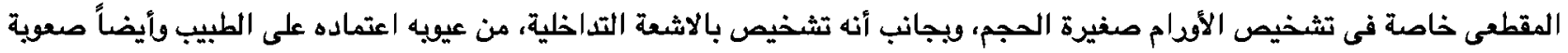

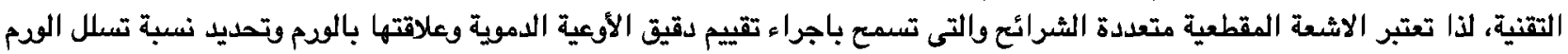

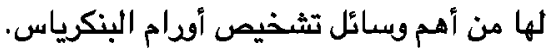

